\title{
Social Value Evaluation of Forest Resource Asset of Forest Industry Zone in Heilongjiang Province
}

\author{
—Based on AHP (Analytic Hierarchy Process)
}

\author{
Jiang Peng \\ BAAFS Agricultural Comprehensive \\ Development Research Institute, \\ Beijing 100097, China \\ jiangpeng0451@126.com
}

\author{
Zhou Liandi \\ BAAFS Agricultural Comprehensive \\ Development Research Institute, \\ Beijing 100097, China \\ haoli9090990@163.com
}

\author{
Hao Li \\ BAAFS Agricultural Comprehensive \\ Development Research Institute, \\ Beijing 100097, China \\ zhouliandi@163.com
}

\begin{abstract}
Along with the establishment of our country's market economy system, forest resources started to be regarded as a kind of asset, and it has been generally accepted after 20 years' progress. Recent years, there have been some evaluation methods to evaluate the value of forest resource asset, but has not been a universal one yet, especially that there are few evaluation towards the value of regional forest resource asset. Based on AHP research method, the article evaluated the social value of forest resource asset of forest industry zone in Heilongjiang province, clarified the interval level, which the social value of this region's forest resource asset was in, and indicated the development direction in the future.
\end{abstract}

Keywords-AHP research method; forest resource asset; evaluation model

\section{INTRODUCTION}

In the 1990s, along with the establishment of our country's market economy system, forest resources started to be regarded as a kind of asset, and it has been generally accepted after 20 years' progress. The essence of Forest resource capitalization is to translate forest resource into assets, monetize it, keep and rise in value of forest resource by market operations, and let the consumption of forest resource can be compensated in value forms and sustainably utilized in material forms. What's more, it can create a virtuous circle of forestry development, which use resource to support resource, in order to create conditions for the practice of forest resource sustainability.

Along with the social viewpoint, which regards forest resource as asset, becoming extensive and incisive, it proves that forest resource asset does have some other values besides its economic value. People start to accept the other values of forest resource asset step by step, and it is followed by the evaluation problems about the value of forest resource asset. The Forest Industry Zone of Heilongjiang Province is one of the four biggest Forest Industry Zones in China. The exact evaluation of its forest resource asset can help to solve the Externalities problems that cause by forest resource services, research the establishment of resource utilization and development plan about welfare maximization in Forest Industry Zone, facilitate the policy-making about coordinate development of forestry zone and local government, and offer experiences to other Forest Industry Zone in China when they research and draft similar regional development strategies. Considering there is less evaluation on regional forest resource asset, and the evaluation methodologies are still not uniform, the article will be based on the relative researches, using AHP theory to build the social value evaluation model about forest resource asset of Forest Industry Zone in Heilongjiang province to conduct quantitative analysis and qualitative evaluation about its social value.

\section{BRIEF INTRODUCTION OF AHP}

AHP ( Analytical Hierarchy Process ) is a multi-objective decision analytical method, which was proposed by an American operational research expert T.L.Saaty in 1970s, that combined quantitative with qualitative. It is suitable to solve complex decision problems and is widely used in every area due to its high logicality, systematicness, flexibility and such features.

AHP can make quantitative descriptions to people's subjective judgments and utilize mathematical method to describe problems that need to be solved. It is suitable to complex systems which are multi-objective, multi-criteria and hard to be fully quantified. Viewed from the specific method, AHP is a weighted sum method, and is one of the most important method to solve multi-objective problems.

According to the nature of the problems and the requirement of the evaluation, AHP decomposes the evaluation problems into different components. Also, it gathers the elements in different levels on the basis of the correlation, interaction and subordination between the elements, in order to form an multilevel, organized and clear-relative analysis evaluation structure model. When applying AHP, decision makers can do some simple judgments, comparisons and calculations, evaluate different elements and make decisions by decomposing complex problems into several levels and elements. 


\section{BUILD THE SOCIAL VALUE EVALUATION MODEL OF FOREST RESOURCE ASSET OF FORESTRY INDUSTRY ZONE IN HEILONGJIANG PROVINCE}

The social value evaluation criterion of forest resource asset is comparatively complex. It has many influencing factors, and there are both mutual benefit and reciprocity and mutual repulsion among those factors. Moreover, changes of some elements can bring about the change of result of the whole social value evaluation. Therefore, we should stick to the principles of systematicness, scientificity, guiding, generality and feasibility in order to build a scientific, feasible, credible, authentic and practical evaluation index of the social value evaluation of forest resource asset.

\section{A Election of the evaluation factors}

Build hierarchical structure table in accordance with the existing research foundations and synthesizing the characters of the forest resource asset of Forest Industry Zone in Heilongjiang province.

TABLE 1 HIERARCHICAL STRUCTURE OF FOREST RESOURCE ASSET’S SOCIAL VALUE OF THE FOREST INDUSTRY ZONE IN HEILONGJIANG PROVINCE

\begin{tabular}{|c|c|c|}
\hline Target Layer & Criteria Layer & Factor Layer \\
\hline \multirow{12}{*}{$\begin{array}{c}\text { Forest Resource Asset's Social } \\
\text { Value of Forest Industry Zone } \\
\text { in Heilongjiang } A\end{array}$} & \multirow{2}{*}{ Civilization B1 } & Forest Culture C1 \\
\hline & & Labor Productivity C2 \\
\hline & \multirow{2}{*}{ Health Physical Treatment B2 } & Population and Life Span C3 \\
\hline & & Recuperation and Health Keeping C4 \\
\hline & \multirow{2}{*}{ New Industry B3 } & Forest Recreation C5 \\
\hline & & Industrial Distribution C6 \\
\hline & \multirow{2}{*}{ Employment and People’s Livelihood B4 } & Employment Value C7 \\
\hline & & Effective Employment C8 \\
\hline & \multirow{4}{*}{ Wonderful Life B5 } & Income Level C9 \\
\hline & & Social Security C10 \\
\hline & & Housing Condition C11 \\
\hline & & Public Security C12 \\
\hline
\end{tabular}

Introductions to the evaluation factors, which can be practically calculated, in the Hierarchical Structure Table:

\section{1) Index $B_{1}-$ Civilization}

Forest Culture $\mathrm{C}_{1}$ : Ration of per capita expenditure spent on culture consumption between residents in Forest Industry Zone and residents in Heilongjiang province.

Labor Productivity $\mathrm{C}_{2}$ : Percentage of year-on-year growth between GDP of Forest Industry Zone share of GDP in Heilongjiang province and that of last year.

\section{2) Index $B_{2}$ - Health Physical Treatment}

Recuperation and Health Keeping $\mathrm{C}_{4}$ : The gap between average value of residents medical treatment payment in Forest Industry Zone and that in Heilongjiang province, then add it to the average value of residents medical treatment payment in Heilongjiang province as a numerator, after that, divide by the average value of residents medical treatment payment in Heilongjiang province.

\section{3) Index $B_{3}-$ New Industry}

Forest Recreation $\mathrm{C}_{5}$ : Ratio of per capita income between touring industry in Forest Industry Zone and that in Heilongjiang province.

\section{4) Index $B_{5}$ - Wonderful Life}

Income Level $\mathrm{C}_{9}$ : Ratio of annual average wage between employees of forestry system in Forest Industry Zone and employees of non-private enterprise in Heilongjiang province.
Housing Condition $\mathrm{C}_{11}$ : Calculate according to ratio between house value of fixed investments of forestry in Forest Industry Zone and hose investment of fixed investments of farmers in Heilongjiang province.

\section{$B \quad$ Weight determination and the sequence of evaluation factors}

In order to avoid the impact of personal judgments on research result and improve the normalization of the research, the scoring system of the article is conducted in the form Delphi Method-that the experts are not allowed to discuss with each other and have horizontal connections, the only thing they can do is to contact with investigators. Eventually, by multi-round investigations, we can gather the experts' roughly identical opinions, which are result from consulting, concluding and modification repeatedly, as the predicted result. The purpose of the questionnaire is to acquire the pairwise comparative result of the significance of every elements. Therefore, we distribute 12 questionnaires ( 2 of each bureau) to the experts and technicists in the area of forest resource asset, who come from Forest Industry Head Office in Heilongjiang Province, Provincial Department of Forestry in Heilongjiang Province, Institute of Nature and Ecology of Academy of Science in Heilongjiang Province, Northeast Forestry University, Heli Forestry Bureau and Hongxing Forestry Area. After sorting and analyzing the data, it can be seen that the experts' opinions have better consistency. Then draw the following results(see Table 1 and Figure 1) by applying AHP software-yaahp to analyze. 


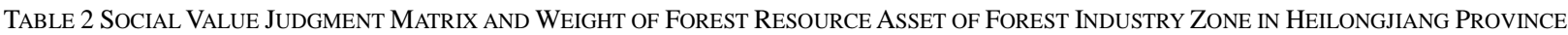
CONSISTENCY RATIO OF JUDGMENT MATRIX: 0.0152; WEIGHT TO THE GENERAL GOAL: $1.0000 ; \backslash$ LAMBDA_\{MAX\}： 5.0680

\begin{tabular}{|c|c|c|c|c|c|c|}
\hline $\begin{array}{c}\text { Forest Resource Asset’s } \\
\text { Social Value of Forest } \\
\text { Industry Zone in Heilongjiang }\end{array}$ & Civilization & $\begin{array}{c}\text { Health Physical } \\
\text { Treatment }\end{array}$ & New Industry & $\begin{array}{c}\text { Employment and } \\
\text { People's Livelihood }\end{array}$ & Wonderful Life & Wi \\
\hline Civilization & 1.0000 & 0.2000 & 0.5000 & 0.2500 & 0.3333 & 0.0606 \\
\hline New Industry & 2.0000 & 0.2000 & 1.0000 & 0.3333 & 0.5000 & 0.0919 \\
\hline $\begin{array}{c}\text { Employment and People’s } \\
\text { Livelihood }\end{array}$ & 4.0000 & 0.5000 & 3.0000 & 1.0000 & 2.0000 & 0.2595 \\
\hline Wonderful Life & 3.0000 & 0.3333 & 2.0000 & 0.5000 & 1.0000 & 0.1579 \\
\hline
\end{tabular}

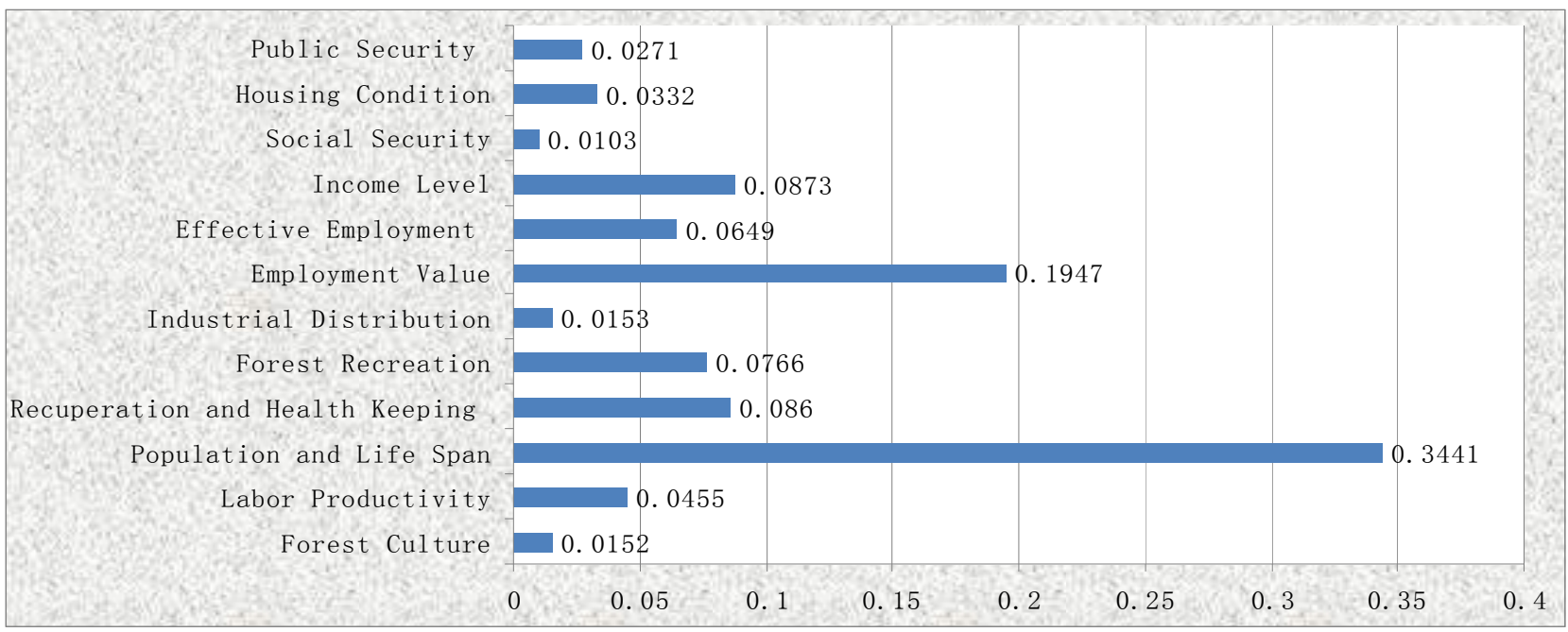

Figure 1 Weight Sequencing by Evaluation Factors of Forest Resource Asset’s Social Value of Forest Industry Zone in Heilongjiang

After testing, single sequencing and overall sequencing all pass consistency test. Therefore, modeling and expert's grading are reasonable.

\section{Quantization of the evaluation factors}

As the qualitative indexes, which are involved in the social value evaluation index system of forest resource asset of Forestry Industry Zone in Heilongjiang province, have strong ambiguity. Therefore, we can apply the form of questionnaire and quantify it by computer. For example, there are all qualitative evaluation indexes except Forest Culture C1, Labor Productivity C2, Recuperation and Health Keeping C4, Forest Recreation C5, Income Level C9 and Housing Condition C11, which are specific numbers that can be acquired by direct or indirect calculation in the 12 three-level indexes. Their scores can be acquired by questionnaire and computer processing; rule of scoring is to take 100 as full mark, and five levels-excellent(100), fine(80), middle(60), low(40) and bad(20). (see Table 3)

TABLE3 VALUES OF 6 FACTORS IN SOLUTION LEVEL SCORED BY EXPERTS

\begin{tabular}{|c|c|c|}
\hline Evaluation Factors of Factor Layer & Results of Experts Scoring & Remark \\
\hline Population and Life Span & 95 & \\
\hline Industrial Distribution & 60 & Take 100 as full mark, and five levels-excellent(100), fine(80), middle(60), low(40) \\
\hline Employment Value & 85 & and bad(20). \\
\hline Effective Employment & 72 & \\
\hline Social Security & 55 & \\
\hline Public Security & 70 & \\
\hline
\end{tabular}

Note: The 12 experts who scored are from Forest Industry Head Office in Heilongjiang Province, Provincial Department of Forestry in Heilongjiang Province, Institute of Nature and Ecology of Academy of Science in Heilongjiang Province, Northeast Forestry University, Heli Forestry Bureau and Hongxing Forestry Area. 
TABLE4 VALUES OF 6 APPRAISAL FACTORS IN SOLUTION LEVEL

\begin{tabular}{|c|c|c|}
\hline \multicolumn{2}{|c|}{ Evaluation Factors of Factor Layer Specific Calculation Result } & Relevant Data \\
\hline Forest Culture & 29.31 & The per capita expenditure spent on culture consumption of residents in Forest Industry \\
\hline & & $\begin{array}{c}\text { Zone is } 324.48 \text { yuan; The per capita expenditure spent on culture consumption of residents } \\
\text { in Heilongjiang province is } 1106.95 \text { yuan. }\end{array}$ \\
\hline Labor Productivity & 72.95 & $\begin{array}{c}\text { GDP of Forest Industry Zone is } 29.689 \text { billion yuan and GDP of Heilongjiang province is } \\
828.800 \text { billion yuan in 2009; And that in is } 17.250 \text { billion yuan and } 831.440 \text { billion yuan } \\
\text { respectively. }\end{array}$ \\
\hline Recuperation and Health Keeping & $110.06 \star$ & $\begin{array}{l}\text { The average value of residents medical treatment payment in Forest Industry Zone is } 570.50 \\
\text { yuan per person; that of residents in Heilongjiang province is } 634.30 \text { yuan per person. }\end{array}$ \\
\hline Forest Recreation & 43.22 & $\begin{array}{l}\text { The general income of touring industry in Forest Industry Zone is } 1.170 \text { billion yuan, } \\
\text { receiving } 4.84 \text { million tourists; The general income of touring industry in Heilongjiang } \\
\text { province is } 60.600 \text { billion yuan, receiving } 108.44 \text { million tourists. }\end{array}$ \\
\hline Income Level & 40.98 & $\begin{array}{l}\text { Annual average wage of employees of forestry system in Forest Industry Zone is } 10874.00 \\
\text { yuan; That of employees of non-private enterprise in Heilongjiang province is } 26535.00\end{array}$ \\
\hline Housing Condition & 26.50 & $\begin{array}{l}\text { yuan. } \\
\text { House value of fixed investments of forestry in Forest Industry Zone is } 2.035 \text { billion yuan; } \\
\text { hose investment of fixed investments of farmers in Heilongjiang province is } 7.679 \text { billion } \\
\text { yuan. }\end{array}$ \\
\hline
\end{tabular}

Note: All of the relevant data are checked from the Statistics Compilation of Forest Industry in Heilongjiang Province (2010) and the Statistical Yearbook of Heilongjiang Province (2010). The theoretical value of each factor is between 0 and 100 , takes it as 100 if it is greater than 100 , take it as 0 if it is less than 0 , and remarks the value out of limit by “ $\star$ ”.

\section{Determination of social value's suit region}

According to the evaluation model formula of forest resource asset's social value of Forest Industry Zone in Heilongjiang province:

$$
A=\sum_{i=1}^{n} P_{i} Q_{i} \quad(i=1,2, \ldots, 12)
$$

Thereinto, A represents the comprehensive value of forest resource asset's social value of Forest Industry Zone in Heilongjiang province; $Q_{i}$ represents the weight of the ith evaluation factor in the Factor Layer; $P_{i}$ represents the score of the ith evaluation factor in the Factor Layer.

According to the weight of total sorts(Figure 1) and the value of evaluation factors in Factor Layer( Table 3 and 4), the comprehensive value of forest resource asset's social value of Forest Industry Zone in Heilongjiang province can be calculated-77.4147.

By Using Rank Value Method for reference, referring to the existing evaluation criterion of forest resource asset, we can divide the value of forest resource asset into 4 levels (see Table 5), determine which level that the forest resource asset's social value of Forest Industry Zone in Heilongjiang province should be in so that they can position themselves more easily, clear the next objective, improve the ability of sustainable development of forest resource asset of Forest Industry Zone in Heilongjiang province more practically.

TABLE 5 EVALUATION CRITERION OF FOREST RESOURCE ASSET

\begin{tabular}{ccccc}
\hline $\begin{array}{c}\text { Comprehensive } \\
\text { value }\end{array}$ & $\leq_{55}$ & $55-75$ & $75-90$ & $>90$ \\
\hline Total value & Lower & Medium & Greater & High \\
\hline
\end{tabular}

According to the table above, the comprehensive value of forest resource asset's social value of Forest Industry Zone in Heilongjiang province is 77.4147 , lies between 75 and 90 , states that it has greater social value. Therefore, on that basis, we can raise it to the high level by more reasonable management tool.

\section{Analysis of the eValuation Results}

\section{A In weight aspect}

We can see from Figure 1 that the top three factors in the weight sort of forest resource asset's social value of Forest Industry Zone in Heilongjiang province are Population and Life Span(0.3441), Employment Value(0.1947) and Income Level(0.0873), the total weight of them is 0.6261 - over $60 \%$. It represents that they can be a decisive role to forest resource asset's social value. However, the other factors just have influencing effect on forest resource asset's social value, and don't have decisive effect.

Forest resource asset's social value of Forest Industry Zone in Heilongjiang province is most embodied in extending people's life, which is be pursued by humans from the beginning to the end. Humans put a lot of material, financial resource and labor into this aspect, the only purpose is to extend life as long as possible. Along with the progress of the society and the improvement of the life quality, people pay more attention to health. People place themselves in the forest area, smelling the fresh air and hearing the song of the birds, escaping from the noising city for a moment. In that way, people can acquire great relax and satisfaction, involuntarily extend their life. The best wealth is to be alive, and this is the most powerful proof to prove that Population and Life Span is the decisive factor among the evaluation factors in forest resource asset's social value.

Employment Value is the indirect reflection of forest resource asset's social value of Forest Industry Zone. Nowadays, problem of employment is a social issue. A large numbers of social idlers have nothing to do, and are the great hidden trouble to maintain social stability. Therefore, the most effective way to remove the hidden danger is to increase employment rate. A lot of working positions can be derived from forest resource asset so that these idlers can be 
employed and also can extend the industry chain by connecting with other industries.

Income level shows the living condition of employees in forest area which means they depend on the environment. The level of the affluence can represent the economic development level of the whole forest area, which is determined by their best wealth - forest resource asset. Only when the employees of the forest area are made to be rich, it is deserved to be called high forest resource asset's social value of Forest Industry Zone.

\section{$B \quad$ In scoring aspect}

We can see from Table 4 that the score of Recuperation and Health Keeping is 110.6, already exceed the max of the practical value 100 . It speaks volumes for their enjoying of the favorable environment that the forest provides. That makes they healthy in body, and reduce the expenditure on medical cost. However, each coin has two sides. In Table 4, the score of Forest Culture is 29.31, the score of Forest Recreation is 43.22, the score of Income Level is 40.98 and the score of the Living Condition is 26.50, they are all below 55 and in the lower level. It can be seen that the culture entertainment of the residents there is very boring in the forest culture aspect. For this reason, we should increase the infrastructure construction in the forest area, encourage the neighborhood committee there to hold culture entertainment positively, raise their positivity and enrich their cultural life. Moreover, it can be seen that the speed of forest tourism development there is extremely slow in the Forest Recreation aspect. The development of the forest tourism has great potential, and the developmental direction is to promote ecotourism and green tourism. Therefore, we should focus on the development of forest tourism, in order to make it superior and good taste. Also, it can be seen that the income of the residents there is very low in the Income Level aspect, only accounting for $40 \%$ that of employees in Heilongjiang province. Therefore, department in charge of forestry should lead the residents their to create income and utilize the effective value of the forest resource asset there according to the practical situation there. Finally, it can be seen that the living condition there is extraordinarily bad; however, residence is the most basic requirement to live. Therefore, we should seize the favorable policies conducted by the government to build a new socialist countryside, positively build a new socialist forest area, and give a fundamental change to the living condition of the residents in the forest area.

\section{REFERENCES:}

[1] Hao Yanping, Chen Longyong, Tao Xiao. Lightly Talking about Management of Forest Resource Asset. Chinese Agricultural Science Bulletin,2009(05)

[2] Yuan Lihong, Wang Yufang. Research on the efficient utilization of forest resource of Forest Industry Zone in Heilongjiang Province. China Forestry Economy,2009(4)

[3] Zhao Hong. Application of AHP in the quantitative analysis .China Public Security-Academic Edition,2010

[4] Guan Hui, Liao Yongzheng, Hu Mengsu. Analysis on the main influencing factors of coal mine safety based on AHP. Shandong Coal Science and Technology,2010(1)

[5] Zhang Changjie, Zhao Xiaoling.Discuss on the evaluation of forest resource asset. Modern Agricultural Science and Technology,2007(10) 